Original Article (short paper)

\title{
Effectiveness of exercise and health education interventions in Brazilian primary health care
}

\author{
Maria Clara Elias Polo ${ }^{1}$ (1) , Giselle Helena Tavares² (1) , Ana Carolina Kanitz ${ }^{3}$ (1) , Emerson Sebastião ${ }^{4}$ (1) , \\ Camila Bosquiero Papini ${ }^{5}$ \\ ${ }^{1}$ Universidade de São Paulo, Programa de Pós Graduação em Saúde Pública, São Paulo, SP, Brasil; ${ }^{2}$ Universi- \\ dade Federal de Uberlândia, Faculdade de Educação Física e Fisioterapia, Uberlândia, MG, Brasil; ${ }^{3}$ Universi- \\ dade Federal do Rio Grande do Sul, Escola da Educação Física, Fisioterapia e Dança, Porto Alegre. RS, Bra- \\ sil; ${ }^{4}$ Northern Illinois University, Department of Kinesiology and Physical Education, DeKalb, IL, United States; \\ ${ }^{5}$ Universidade Federal do Triângulo Mineiro, Departamento de Ciências do Esporte, Uberaba, MG, Brasil
}

\begin{abstract}
Aim: This study examined the effectiveness of two different behavioral change interventions to improve Physical Activity (PA) and to reduce Sedentary Behavior (SB) in a primary health care setting. Methods: This quasiexperimental study recruited and enrolled 31 users of a primary health care unit of the Brazilian Unified Health System aged 18 or more. Participants were allocated into two groups: Physical Exercise Group combined with Health Education (EHE) and Health Education Group (HE). The EHE group participated in 60 minutes of exercise, twice a week, and 20 minutes of counseling. The HE group participated in 40 minutes of counseling, once a week. Both programs were conducted for over 18 weeks. PA levels were self-reported (IPAQ) and PA and SB were objectively (accelerometer) assessed before and after the intervention period. Data were analyzed using intention-to-treat analysis with generalized estimating equations adopting $\mathrm{p}<0.05$ for significance. Also, the individual PA and SB deltas were computed. Improvements in PA and SB were observed for both interventions $(\mathrm{p}<0.05)$. Results: Both groups increased the minutes of weekly leisure PA ( $p=0.006)$, time spent in light $(\mathrm{p}=0.003)$, and moderated-to-vigorous $(\mathrm{p}=0.042) \mathrm{PA}$ and decreased the amount of SB, with a significant decrease in the HE group $(\mathrm{p}=0.010)$. Delta analyses further demonstrated the effectiveness of the interventions to increase PA in other domains (i.e., transportation, household) and maintenance of occupational PA. Conclusion: Behavioral change interventions in the primary health care context involving exercise and counseling seem to be effective in improving PA and SB in adults.
\end{abstract}

Keywords: sedentary behavior; primary health care; exercise; health education

\section{Introduction}

Due to the high rates of non-communicable diseases (NCDs; e.g. cardiovascular diseases, diabetes, cancer) observed around the globe, NCDs lead to major discussions on health promotion and prevention in Public Health. In fact, the United Nations General Assembly recently adopted the Sustainable Development Goals (SDGs), which established that one of the specific objectives of the 17 global goals is to reduce premature mortality due to NCDs by a third until $2030^{1}$. The current scenario is relatively far from this goal. In 2016, 41 million deaths were caused by NCDs. In order to achieve the proposed goal by 2030, efforts will have to be placed in areas to help to improve unhealthy diets, reducing alcohol intake, improving the system for the early detection of diseases, and increasing physical activity levels (PAL) in the population ${ }^{2}$.

There is compelling evidence of the detrimental health effects of a physically inactive lifestyle ${ }^{3-5}$ and other harmful health behaviors, such as a sedentary lifestyle. To this end, it is important to devise initiatives related to exercise and physical activity promotion as well as transdisciplinary health education strategies (e.g., counseling) for the adult population. This is important because, through these types of programs, the population will be able to have access to updated information on health issues, quality of life, and specifics of PA practice; which may help to increase long-term adherence.

Among the possibilities of actions involving interventions with exercise, counseling, and health education aiming at increasing PAL of the population, public spaces for health promotion actions should be considered. In Brazil, the Brazilian public health system (named Unified Healthy System - SUS) is the only access to health care services for about 140 million Brazilians; with a study ${ }^{6}$ showing that $47.9 \%$ of these indicated the Basic Health Care Centers as their main gateway to health services. The high use of health care centers in Brazil makes these places a key setting due to its great potential for scalable health interventions?

To this end, the present study examined the effectiveness of two distinct interventions (i.e., exercise combined with health education and health education alone) carried out at a Primary Health Care (PHC) Centers in Brazil on physical activity (PA) and sedentary behavior (SB) in adults. 


\section{Materials and Methods}

This was a quasi-experimental study ${ }^{8}$, that was carried out at two selected "Basic Health Units" (BHU) in the city of UberabaMG, Brazil.

Firstly, a list of all BHU in Uberaba was acquired along with the city's Health Department. From the list, a research investigator contacted the BHU coordinators via telephone, provided a brief explanation about the study, and asked them about their potential interest in implementing the interventions. The research investigator further inquired the BHU coordinators about the availability of infrastructure and logistical for the interventions. Based on the information provided by the coordinators, two BHUs considered were eligible to receive the interventions. The selected BHUs were chosen because they had available internal space for the counseling meetings and had adequate space to conduct the physical exercise intervention program. The selection of the BHU that would receive each intervention was not randomized but rather based on the infrastructure. The authorization to conduct the study in the BHU was obtained from the Health Department of Uberaba before the beginning of the study. The interventions delivered in this research study are part of the Saúde Ativa Program.

The Saúde Ativa Program started in 2001 in the city of Rio Claro, São Paulo, conceived by the Department of Physical Education of the University of the State of São Paulo in partnership with the Health Foundation of the previously mentioned city 9 . A branch of this program was later established in Uberaba (March 2018) with the name of Saúde Ativa Uberaba. The Saúde Ativa Uberaba is under the responsibility of the Sport Sciences Department of the Federal University of Triângulo Mineiro in partnership with the Municipal Health Department of Uberaba - Minas Gerais.

\section{Participants}

Participants enrolled in this study were users of the Brazilian Unified Health System (SUS) and were recruited by convenience. Recruitment involved flyers posted and disseminated, that provided information about the program (e.g., duration, days of the week and schedule), contact with BHU health professionals requesting a patient referral, as well as dialogues held in the BHU with users in the waiting room waiting for their appointment.

The initial sample comprised of 86 participants. Individuals of both sexes, aged 30 and over, were eligible to participate. After the first week of sessions and assessments, 55 participants met the inclusion criteria and were therefore enrolled in the study. Those who did not complete at least $75 \%$ of the intervention sessions were excluded from the analysis, but they were kept in the program. Participants that did not attend the instructions on how to wear the accelerometer device for 7 days, at least 10 hours per day, were also excluded from the analysis. Therefore, the final analytical sample was comprised of 31 participants allocated into 2 groups: Physical Exercise Group combined with Health Education (EHE; n=19) and Health Education Group (HE; n=12). The Research Ethics Committee of the Federal University of Triângulo Mineiro provided ethical approval under number 2.509.019. All participants accepted and signed an Informed Consent term.

\section{Procedures}

Both interventions were 18-week long and were delivered by a trained exercise specialist. The EHE was performed twice a week, with each session lasting 60 minutes. Each session was divided into 40 minutes of exercise and 20 minutes of health education. The sessions were organized as follows: a) warm-up activities (5 minutes); b) main component - aerobic and neuromotor exercises (30 minutes) and; c) cool down - relaxation and stretching activities ( 5 minutes). The exercises were distributed in four-week cycles, in which the volume of neuromotor exercises gradually decreased from the beginning to the end of the month whereas the volume of aerobic exercise increased over time. In the following month, the volume of neuromotor exercises increased throughout the weeks, and the aerobic exercises decreased. Finally, in the last month, the same volume of exercises performed in the first month was carried out, as shown in Figure 1. The aerobic exercises included walking (in higher volumes) dancing activities, aerobic exercise with sticks, games requiring aerobic abilities, and exercises in circuits. Neuromuscular exercises included activities of strength/muscular resistance, balance, agility, flexibility, and coordination such as yoga and pilates exercises that were proper for the infrastructure, and functional training. Low-cost materials were used during the exercise sessions: plastic bottles filled with sand, broomsticks, cones, and mats. The 20 minutes with health education for this group was organized as follows: a) 5-7 minutes were reserved for general questions to understand the participants' knowledge on certain topics (e.g., Does anybody know what "SB" means?). The remaining time was used to provide group counseling of various health-related topics. The exercise sessions and health education sessions for the EHE group took place in a community sports center located next to the BHU.

The HE intervention was performed at the BHU facility, once a week, with a duration of 40 minutes. This intervention included expository and dynamic lectures, as well as group activities (e.g., Quizzes or Dynamic Games with class contents). Of note, all activities were grounded upon the Transtheoretical Model of Health Behavior ${ }^{10}$. This model guides all multidisciplinary interventions of the Brazilian Public Health System. The counseling part involved health-related topics, including aspects of PA. The HE intervention was led by two nutritionists that comprised the BHE staff team and the topics addressed in this group were the same as those discussed in the EHE (e.g., "Exercise and Physical Activity: Why? What for? When? Where?"; "Sedentary Behavior: A simple act can change your life"; "How to incorporate physical activity in your daily routine?"; "Chronic Diseases and Exercise"; "Stressed out: how physical activity can change your anxiety and stress"; "Nourishment: real food or fake food?"). It is important to highlight that the topics and the methodological strategies adopted were the same for both EHE and HE groups.

PA level was assessed using the International Physical Activity Questionnaire (IPAQ - long form) and through an accelerometer (Actigraph, Pensacola, Florida), which was also used to gather information on SB. The IPAQ questionnaire was administered 7 days before the end of the intervention. During that week, participants were only involved in assessments (i.e., IPAQ and Accelerometer). 


\section{Exercise Volume}

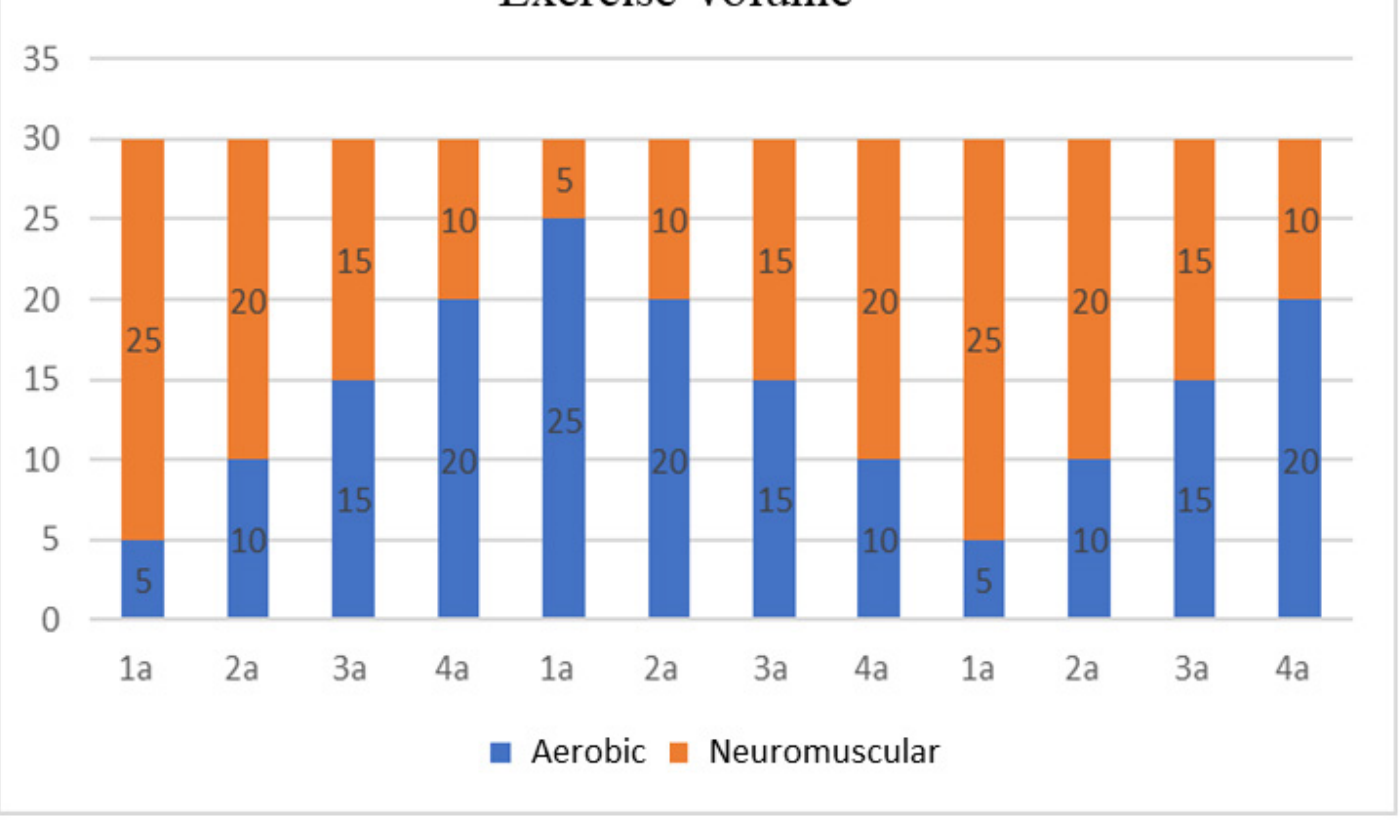

Figure 1 - Exercise Volume distributed in four-week cycles

The IPAQ- long version is a widely accepted instrument used to measure moderate-to-vigorous PA, including walking, in four different domains (leisure, work, transport, and household tasks $)^{11,12}$. The IPAQ was administered face-to-face by research staff with experience in the referred instrument. A domain-specific score (i.e., minutes per week) was calculated for each domain of PA and the total PA score was given by the sum of the number of minutes of total moderate activity for each subdomain, plus two times the number of minutes of vigorous activity, similarly to procedures conducted in previous studies ${ }^{13,14}$. For the purpose of the present study, participants were instructed to consider the time spent during the exercise activities offered by the Program as valid IPAQ data.

Upon the IPAQ-questionnaire completion, accelerometers were further used to assess the PA continuum (i.e., sedentary, light, and moderate-to-vigorous intensity). Participants wore an accelerometer $\left(\mathrm{GT} 3 \mathrm{X}+\right.$ - Actigraph ${ }^{\circledR}$, Pensacola, Florida) on a belt over the right hip for 10 days and at least 10 hours/day14 and were instructed to wear the device from the moment they woke up until the time they went to bed. Participants were further instructed to remove the device for personal hygiene (bathing) and other water activities. The device was set up to record data in a 60-s epoch with a standard drop time of 2 minutes. Analyses included participants with $\geq 7$ valid days $(\geq 600$ min wear time) and two days of the weekend. PA classification (i.e., sedentary, light, moderate, and vigorous) was based on cut-off points of the amount of activity proposed by Sasaki, et al. ${ }^{15}$. Additional SB metrics were calculated based on the accelerometer data, and this included: number of daily breaks in sedentary time, maximal length of sedentary bouts (min), and number of long sedentary bouts. Sedentary breaks refer to the participants' change from sedentary (e.g. sitting quietly and napping) to a non-sedentary activity ${ }^{16}$.
A sociodemographic and health questionnaire was further administered to the participants for sample characterization purposes.

\section{Data Analysis}

Statistical analysis of PAL (IPAQ and Accelerometer), regarding time effect and group effect, and interaction (time $\mathrm{x}$ group) were carried out using Generalized Estimation Equation (GEE), and post hoc analysis was performed with Bonferroni correction. Intention-to-treat analyses were used for the participants that did not attend the last assessment (accelerometer: G1=6 e G2=3; IPAQ: G1=2 e G2=3). Intragroup effect sizes (ES) were calculated using Cohen's ${ }^{17}(1988) d$ test, and coefficients were interpreted as small values $(0,20 \leq d$ $<0,50)$; medium $(0,50 \leq d<0,80)$ and great $(d \geq 0,80)$. The posterior statistical power was calculated using GPower (3.1. version). All analyses were performed using SPSS, version 20 (IBM Corp., SPSS Inc., Armonk, NY), and significance was set at $p<0.05$.

Additionally, individual PAL domains (leisure, work, household tasks, and transport), PA intensity (light, moderate and vigorous), and sedentary behavior (SB) deltas were calculated $($ Delta $=$ post - pre-intervention $)$. Afterward, the number of participants who had positive and negative changes and maintenance were quantified for each group (EHE and HE). Participants without post-intervention assessment were excluded from this analysis.

For the proportion's comparisons, (sociodemographic characteristics and deltas), Fisher Exact test was used. Post hoc analysis was performed by multiple comparisons with Bonferroni correction. 


\section{Results}

The final sample consisted of 31 participants, 19 participants from the EHE group, and 12 from the HE group. Detailed characteristics of the sample are given in table 1 . The majority of the participants was women, being nearly $89 \%$ in EHE and $67 \%$ in the HE group. The mean age of the EHE group was 55 years compared to 51 years of the HE group. Furthermore, the majority of participants in this study reported having one NCD.

Table 2 presents the detailed information on PA assessed by the IPAQ questionnaire. Significant differences were observed for leisure-time PA with both groups increasing leisure PAL in the post-intervention period, but no differences were observed between groups $(p=0.31)$. However, it is important to highlight that when analyzing the $95 \% \mathrm{IC}$ of both groups it is possible to observe that the EHE group does not have its pre- and post-intervention values overlapped, while overlapping is observed for the HE group. This finding may suggest a more positive response to the EHE intervention group. In terms of household-related PA, the analysis revealed a significant difference $(p=0.04)$ between EHE and HE from pre to post-intervention assessments with the HE group presenting higher levels of PA in this domain.
Figure 2A shows the results of the delta ratio for total PA and the leisure, work, transport, and household-related PA domains in EHE and HE. Statistical analysis showed a significant difference in the proportion of participants who increased leisure-time PA in EHE ( $p=0.01$ ) compared to HE. However, although HE did not have the exercise intervention, $45 \%$ of the participants in this group were inclined to improve this PA domain with only health education. No significant differences were observed for all the other domains ( $\mathrm{p}>0.05)$.

Table 3 presents the data on the PA continuum objectively measured through accelerometers. There was a significant time by group interaction on $\mathrm{SB}(\mathrm{p}=0.04)$, with Bonferroni revealing that the reduction of SB significantly occurred in the HE time $(p=0.01)$ and did not significantly occur in the EHE time $(p=0.76)$. Regarding LPA, a significant difference between pre and post-intervention was found $(p=0.003)$, that is, both HE and EHE increased the average time spent in this type of activity. There was no statistically significant time by group interactions on LPA $(p=0.55)$ and $\operatorname{MVPA}(p=0.23)$.

Delta analysis showed that there was no difference between EHE and HE for the proportion of participants who increased, decreased, or maintained SB $(p=0.184), \operatorname{LPA}(p=0.211)$, and MVPA $(p=0.34)$ (Figure 2B).

Table 1 - Sociodemographic profile of the participants in the Saúde Ativa Program.

\begin{tabular}{|c|c|c|c|c|c|}
\hline \multirow[t]{2}{*}{ Variable } & \multicolumn{2}{|c|}{$\operatorname{EHE}(n=19)$} & \multicolumn{2}{|c|}{ HE $(n=12)$} & \multirow[t]{2}{*}{$p$} \\
\hline & $\mathbf{n}$ & $(\%)$ & $\mathbf{n}$ & $(\%)$ & \\
\hline Sex & & & & & 0.14 \\
\hline Female & 17 & 89.5 & 8 & 66.7 & \\
\hline Male & 2 & 10.5 & 4 & 33.3 & \\
\hline Age group & & & & & 0.88 \\
\hline 30 to 40 years old & 1 & 5.2 & 2 & 16.7 & \\
\hline 41 to 50 years old & 4 & 21.1 & 3 & 25 & \\
\hline 51 to 60 years old & 9 & 47.1 & 4 & 33.3 & \\
\hline 61 to 70 years old & 3 & 15.7 & 2 & 16.7 & \\
\hline$>70$ years old & 2 & 10.5 & 1 & 8.3 & \\
\hline Level of Education & & & & & 0.05 \\
\hline Incomplete elementary school & 1 & 5.3 & 3 & 25.0 & \\
\hline Complete elementary school & 11 & 57.9 & 3 & 25.0 & \\
\hline Complete High School & 7 & 36.3 & 5 & 41.7 & \\
\hline Complete Higher Education & 0 & 0 & 1 & 8.3 & \\
\hline Income & & & & & 0.79 \\
\hline$<1$ minimum wage & 3 & 15.8 & 3 & 25 & \\
\hline 1 to 3 minimum wage & 16 & 84.2 & 9 & 75 & \\
\hline NCDs & & & & & 0.51 \\
\hline $1 \mathrm{NCD}$ & 13 & 68.4 & 9 & 75 & \\
\hline 2 or more NCDs & 7 & 36.8 & 3 & 25 & \\
\hline
\end{tabular}

EHE: Exercise and Health Education; HE: Health Education; NCDs: Noncommunicable diseases: obesity, diabetes, hypertension, depression, arthritis, and fibromyalgia 
Table 2 - Mean and Confidence Interval (CI 95\%) of pre- and post-intervention values of physical activity measured through the IPAQ questionnaire separated by intervention groups

\begin{tabular}{|c|c|c|c|c|c|c|c|c|}
\hline \multirow[t]{2}{*}{ Variables (minutes) } & & $\begin{array}{c}\text { EHE }(n=19) \\
\text { mean }(C I 95 \%)\end{array}$ & $\begin{array}{c}\text { HE }(n=12) \\
\text { mean }(C I 95 \%)\end{array}$ & $\begin{array}{c}\text { Interaction } \\
p\end{array}$ & $\begin{array}{c}\text { Time } \\
p\end{array}$ & $\begin{array}{c}\text { Group } \\
p\end{array}$ & Effect Size & Power \\
\hline & Pre & 643.7 (451.5 a 835.9) & 882.9 (541.6 a 1224.2$)$ & & & & & \\
\hline \multirow[t]{2}{*}{ Total PA } & & & & 0.78 & 0.55 & 0.08 & 0.51 & 0.99 \\
\hline & Post & $696.0(520.3$ a 871.8$)$ & $1025.4(557.5$ a 1493.3$)$ & & & & & \\
\hline \multirow{3}{*}{ Leisure PA } & Pre & 80.3 (33.6 a 126.9) & $100.4(47.6$ a 153.2$)$ & & & & & \\
\hline & & & & 0.07 & 0.00 & 0.31 & 0.59 & 1.00 \\
\hline & Post & $202.9(151.5 \text { a } 254.3)^{*}$ & $126.2(63.3 \text { a } 189.2)^{*}$ & & & & & \\
\hline \multirow{3}{*}{ Household PA } & Pre & $336.3(221.77$ a 450.8$)$ & $538.3(222.5 \text { a } 854.1)^{\#}$ & & & & & \\
\hline & & & & 0.60 & 0.86 & 0.05 & 0.66 & 0.99 \\
\hline & Post & $287.4(172.6$ a 402.2$)$ & $632.9(230.1 \text { a } 1035.7)^{\#}$ & & & & & \\
\hline \multirow{3}{*}{ Work-related PA } & Pre & $141.6(-8.0$ a 291.2$)$ & $38.3(-5.8$ a 82.4$)$ & & & & & \\
\hline & & & & 0.06 & 0.98 & 0.93 & 0.37 & 0.97 \\
\hline & Post & $135.8(3.5$ a 268.0$)$ & $41.7(-1.5$ a 84.8$)$ & & & & & \\
\hline \multirow{3}{*}{ Transport-related PA } & Pre & $84.2(38.6$ a 129.8$)$ & $205.8(85.2$ a 326.5$)$ & & & & & \\
\hline & & & & 0.07 & 0.89 & 0.62 & 0.29 & 0.87 \\
\hline & Post & $154.2(51.5$ a 256.9$)$ & $224.6(102.5$ a 346.6$)$ & & & & & \\
\hline
\end{tabular}

Note: SB: Sedentary Behavior; LPA: Light Physical Activity; MVPA: Moderate-to-vigorous physical activity.

$*=$ significant difference in relation to the pre-intervention evaluation;

\# = significant difference in relation to $\mathrm{G} 2$

Table 3 - Mean and Confidence Intervals of 95\% (CI 95\%) of pre- and post-intervention with accelerometer values of the Exercise and Health Education

\begin{tabular}{|c|c|c|c|c|c|c|c|c|}
\hline \multirow{2}{*}{$\begin{array}{l}\text { Variables } \\
\text { (minutes) }\end{array}$} & \multirow{2}{*}{\multicolumn{2}{|c|}{ mean (IC95\%) }} & \multirow{2}{*}{$\begin{array}{c}\text { HE }(\mathrm{n}=9) \\
\text { Mean (IC95\%) }\end{array}$} & \multirow{2}{*}{$\begin{array}{c}\text { Interaction } \\
\quad p\end{array}$} & \multirow{2}{*}{$\begin{array}{c}\text { Time } \\
p\end{array}$} & \multirow{2}{*}{$\begin{array}{c}\text { Group } \\
\quad p\end{array}$} & \multirow[t]{2}{*}{ Effect Size } & \multirow[t]{2}{*}{ Power } \\
\hline & & & & & & & & \\
\hline & Pre & $366.0(268.5$ a 463.6$)$ & $538.1(345.8$ a 731.0$)$ & & & & & \\
\hline \multirow[t]{3}{*}{ SB } & & & & 0.04 & 0.02 & 0.41 & 0.67 & 1.00 \\
\hline & Post & $347.2(275.7$ a 418.8$)$ & $273.0(217.4 \text { a } 330.5)^{*}$ & & & & & \\
\hline & Pre & 296.5 (245.3 a 347.7$)$ & $200(145.6 \text { a } 254.4)^{\#}$ & & & & & \\
\hline \multirow[t]{3}{*}{ LPA } & & & & 0.55 & 0.00 & 0.00 & 0.99 & 1.00 \\
\hline & Post & $386.1(340.1 \text { a } 432.1)^{*}$ & $260.1(217,0 \text { a } 303.2)^{* \#}$ & & & & & \\
\hline & Pre & $37.0(26.0$ a 48.0$)$ & $10.5(7.0 \text { a } 14.0)^{\#}$ & & & & & \\
\hline \multirow[t]{2}{*}{ MVPA } & & & & 0.23 & 0.05 & 0.00 & 0.99 & 1.00 \\
\hline & Post & $42.0(29.5$ a 54.0$)$ & $24.1(16.4$ a 31.8$)$ & & & & & \\
\hline
\end{tabular}

Group (G1) and the Health Education Group (G2)

Note: SB: Sedentary Behavior; LPA: Light Physical Activity; MVPA: Moderate-to-vigorous physical activity.

$*=$ significant difference in relation to the pre-intervention evaluation;

\# = significant difference in relation to $\mathrm{G} 2$ 
A

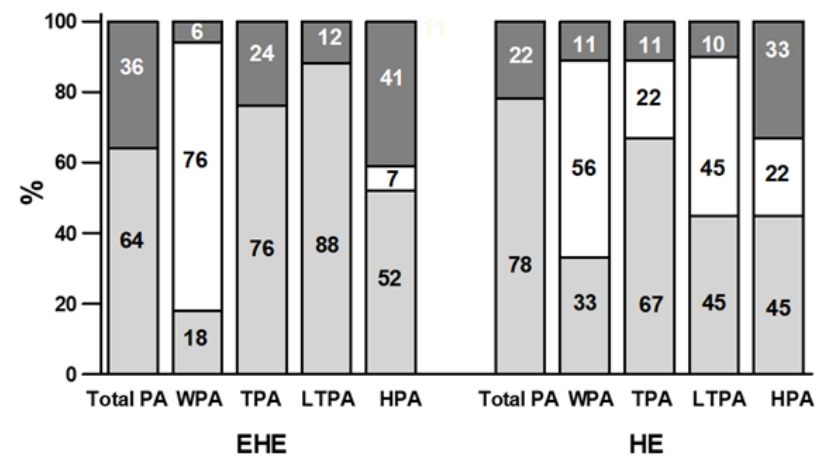

B

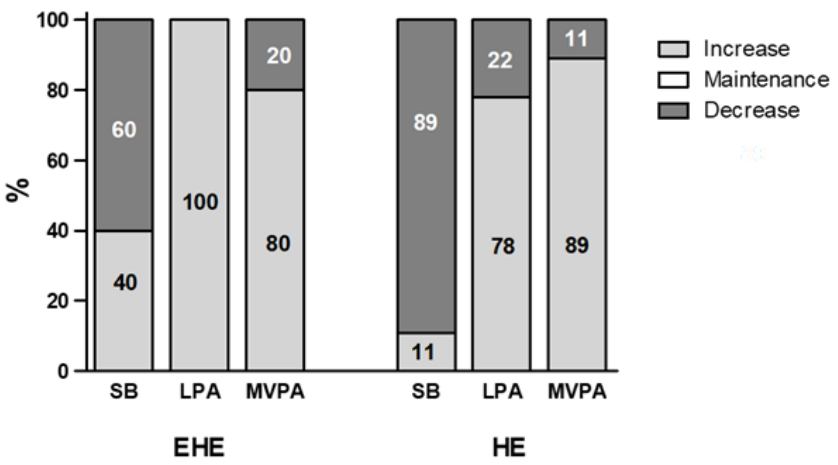

Fig. 2 - A: Delta frequency ( $\Delta=$ post - pre-intervention) for the total PA and leisure, work, transport, and household-related PA domains of the participants of the EHE and HE group. 1B: Delta frequency for the intensity of PA and for the time in sedentary behavior for the participants of the EHE and HE groups. Note:

\section{Discussion}

This study examined the effectiveness of two interventions (i.e., physical exercise combined with health education and health education alone) carried out at BHUs. The main findings were: a) improved leisure, light, and moderate-to-vigorous PAL for both groups, and; b) decreased SB, with significant time by group interaction, revealing that the reduction of SB significantly occurred in the HE group, after 18-weeks.

In order to precede the discussion of our findings, it is imperative to highlight the fact that PA and exercise programs independently of health education are efficient in PHC18-20 and considering that about $75 \%$ of the Brazilian population is exclusively covered by SUS, the availability and democratization of PA practice for the population becomes a key component to prevent the advancement of NCDs in the society.

Regarding the delta analyses, it is worth mentioning that since EHE had exercise as a leisure activity, it is evident that in this domain the EHE had an advantage over HE. From this point of view, it was observed that $88 \%$ of EHE participants increased their leisure PAL. An individual delta analysis was performed in these participants, which indicated that $52 \%$ increased the PA levels beyond the 120 minutes expected for participation in the program $(2 \times 60 \mathrm{~min})$. This is a crucial result, that shows the addition of news physical activities practices in leisure time and highlights the importance of combining the physical exercise practice with health education and counseling (an unusual methodology studied in Brazil). It is also important to note that, although all of the EHE group increased their leisure-time PA, $12 \%$ did not report this practice as a "leisure" activity.
A total of $45 \%$ of HE participants were inclined to improve this PA domain with only health education. This indicates that in places where it is not possible to offer PA for free or if there are insufficient human resources for programmed interventions as exercise programs, health education and counseling activities are also effective in increasing the number of minutes spent on activities in the context of active leisure.

Our findings corroborate the results of previous studies, which emphasize the advantages of health education programs and counseling in the public health field. These programs have shown to be effective in short and medium terms in increasing self-reported leisure, household tasks, transport, and total-related PAL. Furthermore, such types of interventions appear to be effective in increasing health perception, cardiorespiratory fitness, and to positively influence the stage of change and in health $\operatorname{costs}^{21-29}$.

After analyzing PA intensities, evaluated by the accelerometer, it was observed that participants in both EHE and HE groups significantly increased their minutes spent on LPA. By contrast, despite the increase of 80 and $89 \%$ in MVPA (EHE and HE, respectively), no significant differences in MVPA were observed between groups. This result stands out from the others when considering the latest published version of the Physical Activity Guidelines Advisory Committee ${ }^{30}$, which provides evidence that moderate-to-vigorous activities lasting less than 10 minutes are sufficient to obtain the PA benefits in physiological terms such as controlling blood pressure ${ }^{31}$, obtaining positive changes in body composition and weight loss ${ }^{32,33}$, lowering blood glucose levels ${ }^{34}$, and decreasing the risk of metabolic syndrome ${ }^{35}$. According to these findings, the Public Health field should stimulate and 
recommend it for the population, considering any time spent in PA, as long as it is moderate-to-vigorous ${ }^{36}$, without dismissing LPA. There are still few studies investigating the intensity of PA with the use of the accelerometers in adults ${ }^{30}$ and none of them have analyzed the effectiveness and combination of an exercise program and/or health education program.

Regarding SB, due to the evidence that such behavior negatively impacts on the population's health, this topic was present in two complete sessions of health education. This topic was emphasized on other days for the purpose of reminiscing about concepts, definitions, and how small actions matter - like breaks in sitting time. The results showed a significant $\mathrm{SB}$ reduction for both groups, evidencing significant time by group interaction, revealing that the $\mathrm{SB}$ reduction significantly occurred in the $\mathrm{HE}$ time, thereby, highlighting the effectiveness of a health education program in PHC. The possible explanation, in this case, is that the opportunity generated by multidisciplinary educational programs approaching the reality of the population in this health care segment can be considered as a strategy of great influence.

However, articles and evidence regarding health education related to SB and PA only consider one element as the level of impact, or only personal/physiological factors, institutional factors, or only infrastructure ${ }^{30}$. Based on that, the sociodemographic profile data was extremely important for both interventions, but more specifically for the Health Education intervention. Based on this profile, actions and strategies in dialogic education were designed to reach those who did not complete the Basic Education as also those who completed the Higher Education, seeking to consider the whole context involved. Thus, it is necessary to clarify that only providing graphical materials, which is inadequate to the context of the population will hardly affect the individual's behavioral change in this type of action ${ }^{37}$.

The effectiveness of the two types of interventions may have been successful due to the standardization of interventions with more robust strategies, beyond the practice of brief counseling. From these results, effective interventions should include combined actions: behavioral changes with the offer of community programs and educational and behavioral support actions. Additionally, it is of great importance to set tangible goals for the participants in a PHC program, relying on small and medium-sized behavioral changes before any severe change, so the participants will feel motivated to join the program, will become assiduous and active participants in the activity, since it is unequivocal that $\mathrm{PHC}$ represents a door of access of purest interest to the governments, in order to change the behavior of the population.

Despite the evidence on the benefits of providing health promotion activities in $\mathrm{PHC}^{17,26,37,38}$, national public policies have not yet established a pattern of guidance and intervention for these activities. Thus, investigative researches related to this theme are fundamental for the advancement of these policies.

\section{Strengths and limitations}

Our study has some strengths and limitations. One of the strengths of this study is the fact that we employed both objective and self-report assessments of PA and SB, allowing us to acquire quantitative and qualitative data on PA. Our relatively long intervention period and the setting (BHU) can also be considered as a strength of this study. Previous intervention studies were conducted adopting shorter peri$\operatorname{ods}^{30}$. Our findings must be evaluated with caution due to some limitations. We only implemented the interventions in two BHUs, which were not randomized, so we do not know if similar results would be observed if this intervention was implemented in different BHUs, as demographic and other important characteristics of the participants could be different. Furthermore, our study did not include a true control group and our sample size was relatively small. Future studies should include a higher number of BHUs and a true control group. Despite the limitations, we were able to provide preliminary evidence that distinct health behavior interventions may similarly work to improve PA levels of Brazilian adults using the SUS.

\section{Conclusion}

Our study suggests that offering an exercise intervention in combination with health education or health education alone demonstrated to be effective in improving leisure-time PA levels and decreasing SB in adults. Although not significant, our study was promising in increasing PA on other domains (occupational, transportation, household tasks). This trend was observed for both groups. Despite the equivocal results in the literature regarding the effectiveness of health education programs, this study demonstrated the importance of exercise and counseling programs approaches and health education alone to improve PAL and reduce SB in BHUs users in Brazil. Considering the objectives of national policies and governmental actions, these findings are in line with the reality and context of public health in Brazil, becoming major contributions to the health area.

\section{References}

1. ONU. Objetivos de Desenvolvimento Sustentável 1, 2, 3, 5, 9 e 14. Brasília; 2017. http://www.br.undp.org/content/brazil/pt/ home/library/ods/documentos-tematicos--ods-1--2--3--5--9--14. html. Accessed November 9, 2018.

2. OMS. World Health Statistics: Monitoring Health for the SDGs. Luxemburg; 2018.

3. Pate RR, Pratt M, Blair SN, Haskell WL, Macera CA, Bouchard $\mathrm{C}$, et al. Physical activity and public health. A recommendation from the Centers for Disease Control and Prevention and the American College of Sports Medicine. JAMA. 1995;273(5):402407. http://www.ncbi.nlm.nih.gov/pubmed/7823386. Accessed November 9, 2018.

4. Kujala UM, Kaprio J, Sarna S, Koskenvuo M. Relationship of leisure-time physical activity and mortality: the Finnish twin cohort. JAMA. 1998;279(6):440-444. http://www.ncbi.nlm.nih. gov/pubmed/9466636. Accessed November 9, 2018. 
5. Melzer K, Kayser B, Pichard C. Physical activity: the health benefits outweigh the risks. Curr Opin Clin Nutr Metab Care. 2004;7(6):641-647. doi:10.1097/00075197-200411000-00009

6. Brasil. Pesquisa Nacional de Saúde 2013. Rio de Janeiro: Instituto Brasileiro de Geografia e Estatística (IBGE); 2013.

7. Hallal PC, Bauman AE, Heath GW, Kohl HW, Lee IM, Pratt M. Physical activity: More of the same is not enough. Lancet. 2012;380(9838):190-191. doi:10.1016/S0140-6736(12)61027-7

8. Thomas J, Nelson JK, Silverman J. Métodos de Pesquisa Em Atividade Física. 5th ed. Porto Alegre: Artmed; 2007.

9. Nakamura PM, Papini CB, Chiyoda A, Gomes GA de O, Valdanha Netto A, Teixeira IP, et al. Programa de intervenção para a prática de atividade física: Saúde Ativa rio claro. Rev Bras Atividade Física Saúde. 2010;15(2):128-132. doi:10.12820/ RBAFS.V.15N2P128-132

10. Prochaska, J.O. and DiClemente CC. Stages and Processes of Self-Change of Smoking: Toward an Integrative Model of Change. J Consult Clin Psychol. 1983;51:390-395.

11. Marshall A, Bauman A. The International Physical Activity Questionnaire: Summary Report of the Reliability \& Validity Studies.; 2001.

12. Matsudo S, Araújo T, Andrade D, Andrade E, Oliveira LC, Braggion G. Questionário Internacional De Atividade Física (Ipaq): Estudo De Validade E Reprodutibilidade No Brasil. Rev Bras Atividade Física Saúde. 2012;6(2):5-18. doi:10.12820/ rbafs.v.6n2p5-18

13. Hallal P, Victora C, Wells J, RC L. Physical inactivity: prevalence and associated variables in Brazilian adults. Med Sci Sport Exerc. 2003;35(11):1894-900.

14. Sebastião E, Mcauley E, Shigematsu R, Adamson BC, Bollaert RE, Motl RW. Home-based, square-stepping exercise program among older adults with multiple sclerosis : results of a feasibility randomized controlled study. Contemp Clin Trials. 2018;73(June):136-144. doi:10.1016/j.cct.2018.09.008

15. Trost SG, Mciver KL, Pate RR. Conducting accelerometer-based activity assessments in field-based research. Med Sci Sports Exerc. 2005;37(11 SUPPL.):531-543. doi:10.1249/01. mss.0000185657.86065.98

16. Sasaki JE, John D, Freedson PS. Validation and comparison of ActiGraph activity monitors. J Sci Med Sport. 2011;14(5):411416. doi:10.1016/j.jsams.2011.04.003

17. Cohen J. Statistical Power Analysis for the Behavioral Sciences. 2nd ed. Hillsdale: Lawrence Earlbaum Associates; 1988.

18. Jacobson DM, Strohecker L, Compton MT, Katz DL. Physical Activity Counseling in the Adult Primary Care Setting. Am J Prev Med. 2005;29(2):158-162. doi:10.1016/j.amepre.2005.04.009

19. Giraldo A, Gomes G, Serafim T, Zorzeto L, Aquino D, Kokubun E. Influence of a physical activity program on the use of Primary Care services in the city of Rio Claro, SP. Rev Bras Atividade Física Saúde. 2013;18(2):186-196. doi:10.12820/rbafs.v.18n2p186

20. Sanchez A, Bully P, Martinez C, Grandes G. Effectiveness of physical activity promotion interventions in primary care: A review of reviews. Prev Med (Baltim). 2015;76:S56-S67. doi:10.1016/J. YPMED.2014.09.012

21. Eakin EG, Glasgow RE, Riley KM. Review of Primary Care-Based Physical Activity Intervention Studies. J Fam Pract. 2000;49(2):158-158. https://go.galegroup.com/ps/i. $\mathrm{do} ? \mathrm{p}=\mathrm{AONE} \& \mathrm{sw}=\mathrm{w} \& \mathrm{u}=$ googlescholar $\& \mathrm{v}=2.1 \& \mathrm{it}=\mathrm{r} \& \mathrm{id}=-$ GALE\%7CA60039862\&sid=classroomWidget\&asid=135393f5. Accessed November 7, 2018.

22. Foster C, Hillsdon M, Thorogood M, Kaur A, Wedatilake T. Interventions for promoting physical activity. 2013. doi:10.1002/14651858.CD003180.pub2

23. Gomes MA, Duarte MFS. Efetividade de uma intervenção de atividade física em adultos atendidos pela Estratégia de Saúde da Família: Programa Ação e Saúde Floripa - Brasil. Rev Bras Atividade Física Saúde. 2008; 13:44-56. doi:10.12820/ rbafs.v.13n1p44-56

24. Morton K, Beauchamp M, Prothero A, Joyce A, Saunders L, Spencer-Bowdage, S, et al. The effectiveness of motivational interviewing for health behaviour change in primary care settings: a systematic review. Health Psychol Rev. 2015;9(2):205-223. do i: 10.1080/17437199.2014.882006

25. Neidrick TJ, Fick DM, Loeb SJ. Physical activity promotion in primary care targeting older adults. J Am Acad Nurse Pract. 2012;24(7):405-416. doi:10.1111/j.1745-7599.2012.00703.x

26. Orrow G, Kinmonth A-L, Sanderson S, Sutton S. Effectiveness of physical activity promotion based in primary care: systematic review and meta-analysis of randomised controlled trials. BMJ. 2012;344:e1389. doi:10.1136/bmj.e1389

27. Rasmussen SR, Thomsen JL, Kilsmark J, Hvenegaard A, Engberg M, Lauritzen T, et al. Preventive health screenings and health consultations in primary care increase life expectancy without increasing costs. Scand J Public Health. 2007;35(4):365-372. doi:10.1080/14034940701219642

28. Sinclair J, Lawson B, Burge F. Which patients receive advice on diet and exercise? Do certain characteristics affect whether they receive such advice? Can Fam Physician. 2008;54(3):404-412. doi:54/3/404 [pii]

29. van Sluijs EMF, van Poppel MNM, Twisk JWR, Chin A Paw MJ, Calfas KJ, van Mechelen W. Effect of a tailored physical activity intervention delivered in general practice settings: results of a randomized controlled trial. Am J Public Health. 2005;95(10):18251831. doi:10.2105/AJPH.2004.044537

30. Department of Health and Human Services 2018. 2018 Physical Activity Guidelines Advisory Committee Scientific Report. 2018. doi:10.1111/j.1753-4887.2008.00136.x

31. Eguchi M, Ohta M, Yamato H. The effects of single long and accumulated short bouts of exercise on cardiovascular risks in male Japanese workers: a randomized controlled study. Ind Health. 2013;51(6):563-571. doi:10.2486/INDHEALTH.2013-0023

32. Jefferis BJ, Parsons TJ, Sartini C, Ash S, Lennon L, Wannamethee $\mathrm{S}$, et al. Does duration of physical activity bouts matter for adiposity and metabolic syndrome? A cross-sectional study of older British men. Int J Behav Nutr Phys Act. 2016;13(1):36. doi:10.1186/s12966-016-0361-2

33. Cameron N, Godino J, Nichols JF, Wing D, Hill L, Patrick K. Associations between physical activity and BMI, body fatness, and visceral adiposity in overweight or obese Latino and non-Latino adults. Int J Obes (Lond). 2017;41(6):873-877. doi:10.1038/ ijo. 2017.49

34. Wolff-Hughes DL, Fitzhugh EC, Bassett DR, Churilla JR. Total Activity Counts and Bouted Minutes of Moderate-ToVigorous Physical Activity: Relationships with Cardiometabolic 
Biomarkers Using 2003-2006 NHANES. J Phys Act Heal. 2015;12(5):694-700. doi:10.1123/jpah.2013-0463

35. Glazer NL, Lyass A, Esliger DW, Blease S, Freedson P, Massaro J, et al. Sustained and shorter bouts of physical activity are related to cardiovascular health. Med Sci Sports Exerc. 2013;45(1):109115. doi:10.1249/MSS.0b013e31826beae5

36. Saint-Maurice PF, Troiano RP, Matthews CE, Kraus WE. Moderate-to-Vigorous Physical Activity and All-Cause Mortality: Do Bouts Matter? J Am Heart Assoc. 2018;7(6). doi:10.1161/ JAHA.117.007678

37. van Achterberg T, Huisman-de Waal GGJ, Ketelaar NABM, Oostendorp RA, Jacobs JE, Wollersheim HCH. How to promote healthy behaviours in patients? An overview of evidence for behaviour changes techniques. Health Promot Int. 2011;26(2):148162. doi:10.1093/heapro/daq050

38. Rubio-Valera M, Pons-Vigué S M, Martínez-André S M, MorenoPeral P, Berenguera A, Ferná Ndez A. Barriers and Facilitators for the Implementation of Primary Prevention and Health Promotion Activities in Primary Care: A Synthesis through MetaEthnography. PLoS One. 2014;9(2):1-13. doi:10.1371/journal. pone. 0089554

\section{Corresponding author}

Maria Clara Elias Polo

Programa de Pós Graduação em Saúde Pública, Faculdade de Saúde Pública, Universidade de São Paulo. Av. Dr. Arnaldo, 715 - Cerqueira César, São Paulo - SP, 01246-904.

Email: mcepolo@gmail.com

Editor: Danilo Rodrigues Pereira da Silva, UFS/São Cristovão, SE, Brazil

Manuscript received on January 15, 2020

Manuscript accepted on June 4, 2020

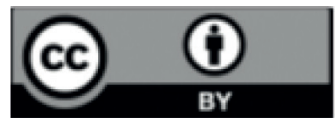

Motriz. The Journal of Physical Education. UNESP. Rio Claro, SP, Brazil - eISSN: 1980-6574 - under a license Creative Commons - Version 4.0 